\title{
The effect of pasture quantity temporal variation on milking robot utilization
}

\author{
A. J. John, ${ }^{1 *}$ B. R. Cullen, ${ }^{2}$ K. Oluboyede,${ }^{2}$ M. J. Freeman, ${ }^{3}$ K. L. Kerrisk, ${ }^{1}$ S. C. Garcia, ${ }^{1}$ and C. E. F. Clark ${ }^{1}$ \\ ${ }^{1}$ Dairy Science Group, School of Life and Environmental Sciences, Faculty of Science, University of Sydney, Camden 2570, Australia \\ ${ }^{2}$ Faculty of Veterinary and Agricultural Sciences, The University of Melbourne, Melbourne 4003, Australia \\ ${ }^{3}$ Tasmanian Institute of Agriculture Dairy Centre, University of Tasmania, Burnie 7320, Australia
}

\section{ABSTRACT}

In pasture-based automatic milking systems (AMS), a decrease in robot utilization (RU) often occurs in the early morning hours. Novel feeding strategies that encourage voluntary cow traffic throughout $24 \mathrm{~h}$ could help mitigate this problem. We determined the effect of 3 distinct pasture allocation methods on RU patterns throughout a 24 -h period. The experiment was conducted at the University of Melbourne's Dookie research farm in northern Victoria, Australia. Three Lely Astronaut A3 robotic milking units (Lely, Maassluis, the Netherlands) milked 133 cows, grazing pasture, with concentrate offered at milking in the robots. The farm operated a system of 3-way grazing, with active access to each pasture allocation: 2030-0400 h (allocation A), 0400-1330 h (allocation B), and 1330-2030 h (allocation C). Treatments varied in the quantity of feed offered per hour of active access to each of the 3 pasture allocations. The control treatment offered the same proportion of feed (corrected for active access time) in all 3 pasture allocations (allocation $\mathrm{A}=$ $31.3 \%, \mathrm{~B}=39.6 \%$, and $\mathrm{C}=29.2 \%$ ). The day treatment offered the largest proportion of feed during the day (allocation $\mathrm{A}=20 \%, \mathrm{~B}=40 \%$, and $\mathrm{C}=40 \%$ ), following the cows' diurnal pattern of feeding activity. The night treatment offered the largest proportion of feed at night (allocation $\mathrm{A}=42 \%, \mathrm{~B}=40 \%$, and $\mathrm{C}=18 \%$ ). Due to the nature of pasture-based AMS, treatments could not be applied simultaneously. Therefore, treatments were applied to the entire herd and repeated twice over $42 \mathrm{~d}$, lasting $7 \mathrm{~d} /$ treatment, with the first $3 \mathrm{~d}$ for habituation, followed by $4 \mathrm{~d}$ of data collection. Robot utilization (milkings/h) varied throughout $24 \mathrm{~h}$ between treatments, with the night treatment recording greater RU at 0800, 1800, and $1900 \mathrm{~h}$ and lower RU between 2100 to $0100 \mathrm{~h}$, compared with the day treatment. The proportion of the herd milking between

Received March 22, 2018.

Accepted November 10, 2018.

*Corresponding author: ajoh7559@uni.sydney.edu.au
0000 and $0600 \mathrm{~h}$ was greater for the control (43.3\%) and day (45.3\%) treatments compared with the night treatment (25.8\%). Herd-average daily pasture intake was similar (10.5 kg of dry matter) for all treatments. This experiment is the first to demonstrate the manipulation of RU by varying the quantity of pasture offered. However, the use of variable allocation alone did not eliminate the decrease in RU between 0000 and $0600 \mathrm{~h}$, with the timing of allocation also likely to play a role. We recommend a further research focus on combining both timing and quantity of pasture allocated to improve RU in pasture-based AMS.

Key words: automatic milking system, milking frequency, grazing, voluntary traffic

\section{INTRODUCTION}

The combination of grazing pasture and automatic milking systems (AMS) is well proven in Australia, with the FutureDairy project demonstrating high levels of pasture utilization can be achieved (Clark et al., 2016). Currently, over 40 farms with AMS are operating throughout Australia, with the majority utilizing grazed pasture as the main feed source. However, combining AMS with grazed pasture presents many unique challenges, with the whole farming system requiring modification to accommodate AMS. An individual robotic milking unit is capable of milking 7 to 8 cows $/ \mathrm{h}$, and establishing an evenly distributed robot utilization (RU) throughout $24 \mathrm{~h}$ is key to the efficiency of the system (Kerrisk, 2010). John et al. (2013) estimated an additional 10 cows/robot could be supported when a consistent RU pattern throughout $24 \mathrm{~h}$ could be achieved. Further, as pasture-based AMS operate a system of semi-forced cow traffic, consistent cow flow to the dairy is essential to avoid extended waiting times, which can have a detrimental effect on animal welfare, especially for low socially ranked cows (Halachmi, 2009). Woolford et al. (2004) suggested milking more cows/robot, potentially improving overall RU, possibly at the expense of milking frequency (MF). A recent study by Lyons and Kerrisk (2017) found 51 cows/robot was the average ratio on Australian AMS farms, with 
farmers opting to milk less cows at greater MF. Lyons and Kerrisk (2017) also determined milkings/robot per day could be further increased by $60 \%$, highlighting the large disparity between current AMS performance in Australia, relative to actual potential.

A reduction in the number of milking events occurring in the early morning hours is often reported in pasture-based AMS, creating inconsistency in RU throughout $24 \mathrm{~h}$ (John et al., 2016b). This decline in RU during the early morning hours is more pronounced in pasture-based systems, compared with indoor systems (John et al., 2016b), which we attribute to the greater synchrony of cows when at pasture, compared with when indoors (Ketelaar-de Lauwere et al., 1999). Other factors may also contribute to inconsistent RU in pasture-based AMS, such as distance to pasture, stage of lactation (SOL), weather conditions, social hierarchy, and feed management. From these factors, feeding management can be readily altered by farmers to manipulate the system.

Feed is the main incentive used to encourage cows to voluntarily traffic throughout an AMS (Prescott et al., 1998) with the variation in RU likely due to the crepuscular nature of cows, with feeding activity peaking at sunrise and sunset and grazing at night accounting for only $15 \%$ of daily grazing time (Stobbs, 1970). Thus, manipulating feeding patterns of cows to be more evenly distributed throughout $24 \mathrm{~h}$ should also provide a benefit to RU. Studies conducted with indoor AMS have concluded increasing concentrate feed at the robot provides no improvement to MF (Halachmi et al., 2005; Bach et al., 2007). Increasing the number of feed allocations from $2 \times$ to $4 \times$ in an indoor dairy system was shown to increase the feeding duration at night by 14 min (DeVries et al., 2005); however, implementing multiple pasture allocations in pasture-based AMS can be complex as individual laneways are usually required for each additional pasture allocation. Lyons et al. (2013) offered 3 allocations of pasture in $24 \mathrm{~h}$ (3WG), rather than 2 pasture allocations as is typical in conventional pasture-based dairy farming, which increased MF and milk yield (MY) by 40 and 20\%, respectively, and reduced extended milking intervals by $31 \%$. John et al.
(2013) associated planned variable pasture allocation in 3 WG with consistent and high RU throughout $24 \mathrm{~h}$ in a commercial pasture-based AMS. While the success of 3WG has seen the practice widely adopted on pasturebased AMS in Australia, farmers still report a drop in RU during the early morning hours.

Despite the importance of RU to AMS, the majority of AMS research has focused on MF, and no research to date has determined the ability to manipulate the temporal distribution of milking events. We determined the effect of temporal variation in pasture allocation on the RU of a pasture-based AMS. We hypothesized that using variable allocation would increase the number of milking events between 0000 and $0600 \mathrm{~h}$. We also hypothesized that MF, MY, and pasture intake would increase, due to better voluntary trafficking on the variable allocation treatments, and in turn reduce extended milking intervals $>16 \mathrm{~h}$.

\section{MATERIALS AND METHODS}

The use of animals was approved by The University of Melbourne Animal Ethics Committee (Project Number: 1413349). The experiment was conducted between November 10 and December 21, 2016, at The University of Melbourne's Dookie Research Farm, Dookie, Victoria, Australia. Heavy rainfall was experienced in the first 2 wk of the experiment, with the weather for the remainder of the experiment typical for November and December (Table 1). The light dark cycle during the experiment was approximately 14 and $10 \mathrm{~h}$, with sunrise and sunset occurring at 0600 and $2000 \mathrm{~h}$, respectively.

Three Lely Astronaut A3 robots milked 143 HolsteinFriesian cows (decreasing to 130 cows as the trial progressed) on a grazing platform of 41 ha. The predominant sward consisted of a perennial ryegrass (Lolium perenne) and white clover (Trifolium repens), with 6 ha of Persian clover (Trifolium resupinatum) also in the grazing rotation. The average quantity of pasture and silage offered (across all pasture allocations) was $7.3 \mathrm{~kg}$ of $\mathrm{DM} /$ cow per day. Clover silage $(\mathrm{DM}=50.0 \%, \mathrm{NDF}$ $=42.0 \%, \mathrm{ADF}=38.6 \%, \mathrm{CP}=17.7 \%$, dry matter digestibility $=59.2 \%, \mathrm{ME}=8.5 \mathrm{MJ} / \mathrm{kg}$ on DM basis) was

Table 1. Weekly (mean \pm SD) minimum temperature (Min $\mathrm{T})$, maximum temperature (Max $\mathrm{T})$, and total rainfall during the experiment, as well as long-term mean ${ }^{1}$ for November and December

\begin{tabular}{|c|c|c|c|c|c|c|c|c|}
\hline \multirow[b]{2}{*}{ Item } & \multicolumn{6}{|c|}{ Week } & \multicolumn{2}{|c|}{ Long-term mean } \\
\hline & Nov. $10-16$ & Nov. $17-23$ & Nov. $24-30$ & Dec. $1-7$ & Dec. 8-14 & Dec. $15-21$ & Nov. & Dec. \\
\hline $\operatorname{Max} T\left({ }^{\circ} \mathrm{C}\right)$ & $22.5 \pm 4.1$ & $29.1 \pm 6.7$ & $25.3 \pm 4.1$ & $29.6 \pm 3.1$ & $27.1 \pm 5.7$ & $26.1 \pm 2.5$ & 26.4 & 29.1 \\
\hline Rainfall (mm) & 29.6 & 24.2 & 0.0 & 4.6 & 3.4 & 2.0 & 51.6 & 32.7 \\
\hline
\end{tabular}

${ }^{1} 20$-yr mean from Bureau of Meteorology (station 81125), Melbourne, Australia. 
Table 2. Experimental treatments (control, day, and night), including proportion of pasture allocated ${ }^{1}$ and proportion of pasture allocated per hour of active access $(\% / \mathrm{h})$, for each pasture allocation ${ }^{2}(\mathrm{~A}, \mathrm{~B}$, and $\mathrm{C})$

\begin{tabular}{lcccccccc}
\hline & \multicolumn{2}{c}{ Allocation $\mathrm{A}$} & & \multicolumn{2}{c}{ Allocation B } & & \multicolumn{2}{c}{ Allocation C } \\
\cline { 2 - 3 } Treatment & Proportion $(\%)$ & $\% / \mathrm{h}^{3}$ & & Proportion $(\%)$ & $\% / \mathrm{h}$ & & Proportion $(\%)$ & $\% / \mathrm{h}$ \\
\hline Control & 31.3 & 4.17 & & 39.6 & 4.17 & & 29.2 & 4.17 \\
Day & 20.0 & 2.67 & & 40.0 & 4.21 & & 40.0 & 5.71 \\
Night & 42.0 & 5.60 & & 40.0 & 4.21 & & 18.0 & 2.57 \\
\hline
\end{tabular}

${ }^{1}$ The mean quantity of pasture and silage offered was $7.3 \mathrm{~kg}$ of DM/cow per d, split across the 3 daily allocations according to the treatment applied.

${ }^{2}$ Allocation A 2030-0400 h, allocation B 0400-1330 h, allocation C 1330-2030 h.

${ }^{3}$ Proportion of feed allocated/hour of active access to allocation.

provided in the paddock to supplement pasture when available pasture biomass was insufficient to maintain the farm's paddock rotation schedule. During the $42-\mathrm{d}$ experiment, silage was offered 7 times in allocation $\mathrm{A}$ $(2.3 \pm 0.0 \mathrm{~kg}), 18$ times in allocation B $(3.1 \pm 0.6 \mathrm{~kg})$, and 14 times in allocation $\mathrm{C}(5.8 \pm 3.3 \mathrm{~kg})$. Cereal grain pellets (OptiMilk Lacta Max, Rivalea Australia Pty. Ltd., Corowa, Australia; $\mathrm{CP}=16 \%, \mathrm{ME}=12.5$ $\mathrm{MJ} / \mathrm{kg}$ of $\mathrm{DM}$ ) were offered at milking, in the robots, at a rate of $5 \mathrm{~kg} / \mathrm{d}$ for cows with MY $<20 \mathrm{~kg}, 7 \mathrm{~kg}$ for MY between 20 and $25 \mathrm{~kg}$, and an extra $1 \mathrm{~kg}$ of pellets offered per $5 \mathrm{~kg}$ of additional MY thereafter. Average pellet consumption was $8.7 \mathrm{~kg}$ of $\mathrm{DM} /$ cow per day during the experimental period. The farm operated a $3 \mathrm{WG}$ system, with 3 allocations of fresh pasture offered per $24 \mathrm{~h}$. Automatic drafting gates, located at the dairy, routed cows to the designated pasture allocation. Milking permission was granted $6 \mathrm{~h}$ following any previous milking event.

\section{Treatments}

Due to the design of pasture-based AMS farms, applying each treatment in duplicate would have required 6 individual farms each with their own AMS. As this was not possible, treatments were applied to the entire herd over a 42-d period, with each treatment lasting for $7 \mathrm{~d}$ and repeated twice (treatment order: day, control, night, day, night, control). Within each $7 \mathrm{~d}$ treatment period, the first $3 \mathrm{~d}$ were a habituation period, followed by $4 \mathrm{~d}$ of data collection. The quantity of pasture offered during the experimental period varied according to treatment (Table 2). Active access times for each pasture allocation were based on the research farm's current operating procedure. Both feed quantity and duration of pasture allocation are used to calculate the proportion of feed offered $(\% / \mathrm{h})$. The control treatment allocated the same amount of feed (corrected for active access time) for all pasture allocations. The day treatment allocated a larger quantity of pasture during the day (allocation C), followed by a smaller quantity of pasture during the night (allocation A). The night treatment allocated a smaller quantity of pasture during the day (allocation C), followed by a larger quantity of pasture during the night (allocation A). For this study, both day and night treatments are considered as methods of variable allocation.

\section{Pasture Measurements}

Pasture measurements occurred every Monday, Wednesday, and Friday for all pasture allocations. Compressed biomass was measured using a calibrated Rising Plate Meter (360 mm diameter, $315 \mathrm{~g}$ plate weight) fitted with an electronic counter (Farmworks, Palmerston North, New Zealand) for pregrazing (before dairy cattle enter the allocated pasture) and postgrazing (after the last cow had exited the allocated pasture). Between 80 and 100 individual pasture height readings were taken across multiple transects (zig-zag pattern) in each paddock, avoiding areas of high cow traffic. The pre- and postgrazing compressed pasture heights were converted to pasture biomass using the formula calibrated for the farm following the method of Earle and McGowan (1979), using 9 calibration cuts taken on November 30, 2016:

biomass $(\mathrm{kg}$ of $\mathrm{DM} / \mathrm{ha})=$ height $(\mathrm{cm}) \times 130-616$.

The area (ha) of each allocation was recorded using a handheld global positioning system (Garmin Ltd., Canton of Schaffhausen, Switzerland). From this, the pasture offered per cow in each individual allocation was determined:

pasture offered $(\mathrm{kg}$ of $\mathrm{DM} / \mathrm{cow})=[$ pregrazing biomass

(kg of DM/ha) - postgrazing target biomass

$$
(\mathrm{kg} \text { of } \mathrm{DM} / \mathrm{ha})] \times \text { area }(\text { ha }) \div \text { herd size. }
$$


Table 3. Mean \pm SD of pasture DM, ADF, NDF, water-soluble carbohydrate (WSC), CP, dry matter digestibility (DMD), and ME on a DM basis and pre- and postgrazing biomass for each treatment (control, day, and night)

\begin{tabular}{lrrr}
\hline & \multicolumn{3}{c}{ Treatment } \\
\cline { 2 - 4 } Item & \multicolumn{1}{c}{ Control } & Day & Night \\
\hline DM (\%) & $26.1 \pm 7.4$ & $22.5 \pm 5.4$ & $26.5 \pm 5.7$ \\
ADF (\%) & $34.8 \pm 1.7$ & $33.3 \pm 3.0$ & $34.9 \pm 3.4$ \\
NDF (\%) & $54.1 \pm 1.7$ & $50.9 \pm 6.2$ & $55.3 \pm 4.8$ \\
WSC (\%) & $7.6 \pm 2.1$ & $8.7 \pm 2.7$ & $8.4 \pm 3.3$ \\
CP (\%) & $14.9 \pm 1.9$ & $15.7 \pm 2.6$ & $15.6 \pm 2.3$ \\
DMD (\%) & $61.2 \pm 1.6$ & $62.7 \pm 2.9$ & $61.3 \pm 3.4$ \\
ME (MJ/kg of DM) & $8.8 \pm 0.3$ & $9.1 \pm 0.5$ & $8.8 \pm 0.6$ \\
Pregrazing biomass (kg of DM/ha) & $2,112 \pm 149$ & $2,151 \pm 217$ & $2,027 \pm 207$ \\
Postgrazing biomass (kg of DM/ha) & $1,570 \pm 132$ & $1,548 \pm 128$ & $1,493 \pm 169$ \\
\hline
\end{tabular}

The postgrazing biomass value was used to determine the average pasture consumed per cow using the following equation:

pasture consumed $(\mathrm{kg}$ of $\mathrm{DM} / \mathrm{cow})=$ [pregrazing biomass (kg of DM/ha) - postgrazing biomass $(\mathrm{kg}$ of $\mathrm{DM} / \mathrm{ha})] \times$ area (ha) $\div$ herd size.

\section{Cow Data}

The Lely milking management software "Time 4 Cows" was used to create custom reports for collection of milking event and animal data. Cow ID, date, time, and milk yield (L) were recorded for each milking event. Daily milk yield (L/cow per d), MF (milkings/cow per d), grain intake ( $\mathrm{kg} / \mathrm{cow}$ per d), SOL (d), and rumination time $(\mathrm{min} / \mathrm{cow}$ per $\mathrm{d})$ were collected in a second report. Cows were required to voluntarily exit each pasture allocation by a predetermined time (allocation $\mathrm{A}=0930 \mathrm{~h}$, allocation $\mathrm{B}=1700 \mathrm{~h}$, and allocation $\mathrm{C}=$ $0730 \mathrm{~h}$ ), cows remaining in the paddock at these times were fetched and guided back to the milking robot.

\section{Pasture Quality}

Pasture samples were collected from all 3 pasture allocations (A, B, C) 3 times/wk, when the pasture measurements were taken. Average pasture quality for each treatment is presented in Table 3. Silage samples were also collected when silage was fed. Dry matter was determined by drying samples for $48 \mathrm{~h}$ at $70^{\circ} \mathrm{C}$, before being ground to pass through a $1-\mathrm{mm}$ sieve. A subsample of the ground feed was used to determine ADF (Ankom Technologies, 2014a) and NDF (Ankom Technologies, 2014b) using an Ankom ${ }^{200}$ fiber analyzer. Total nitrogen was determined by combustion (AOAC International, 1995) using a Leco FP-628 Nitrogen Determinator (Leco Corporation, St. Joseph, MI) and used to calculate $\mathrm{CP}(\mathrm{CP} \%=6.25 \times$ sample nitrogen $\%$ ). Water-soluble carbohydrate was determined by water extraction (AFIA, 2014). Pasture DM digestibility and $\mathrm{ME}$ were determined using the equation reported by Oddy et al. (1983) and Primary Industries Standing Committee (2007), respectively.

\section{Statistical Analysis}

Statistical analysis was performed using Genstat 17th Edition (VSN International, Hemel Hempstead, UK), with significance determined at $P<0.05$. Robot utilization (milkings/h) was determined using REML, with hour $(H ; j=0,1, \ldots, 23)$ and treatment $(T ; i=$ control, day, night) as fixed effects and cow $(C ; k=1$, $2, \ldots, 143)$ and week $(W ; l=1,2, \ldots, 6)$ as random factors, using the following model:

$$
Y_{i j k l}=T_{i}+H_{j}+T H_{i j}+C_{k}+W_{l}+\varepsilon_{i j k l}
$$

where $Y$ is the dependent variable (RU) and $\varepsilon_{i j k l}$ is the random error. The mean daily MF, MY, SOL, and grain intake per cow were determined using REML, with treatment ( $T ; i=$ control, day, night) as the fixed effect and cow $(C ; k=1,2, \ldots, 143)$ and week $(W ; l$ $=1,2, \ldots, 6)$ as random effects, using the following model:

$$
Y_{i k l}=T_{i}+C_{k}+W_{l}+\varepsilon_{i k l}
$$

where $Y$ is the dependent variable (MF, MY, SOL, grain intake, and rumination time) and $\varepsilon_{i k l}$ is the random error. The same model (less $C$ as a random effect) was used to determine the mean daily milking events (MR) and system yield (SY) per robot, where MR and SY were the dependent variables $Y$. The proportion of the herd with a milking event between 0000 and $0600 \mathrm{~h}$ and the proportion of milking events exceeding 16 -h milking 
Table 4. Effects of 3 pasture management treatments (control, day, and night) on predicted mean daily milk yield (L/cow per d), milking frequency (milking events/cow per d), pasture intake ${ }^{1}$ ( $\mathrm{kg}$ of DM/cow per d), grain intake ( $\mathrm{kg} /$ cow per d), rumination time (min/cow per d), milking events (milkings event/robot per d), and system yield (L of milk/robot per d)

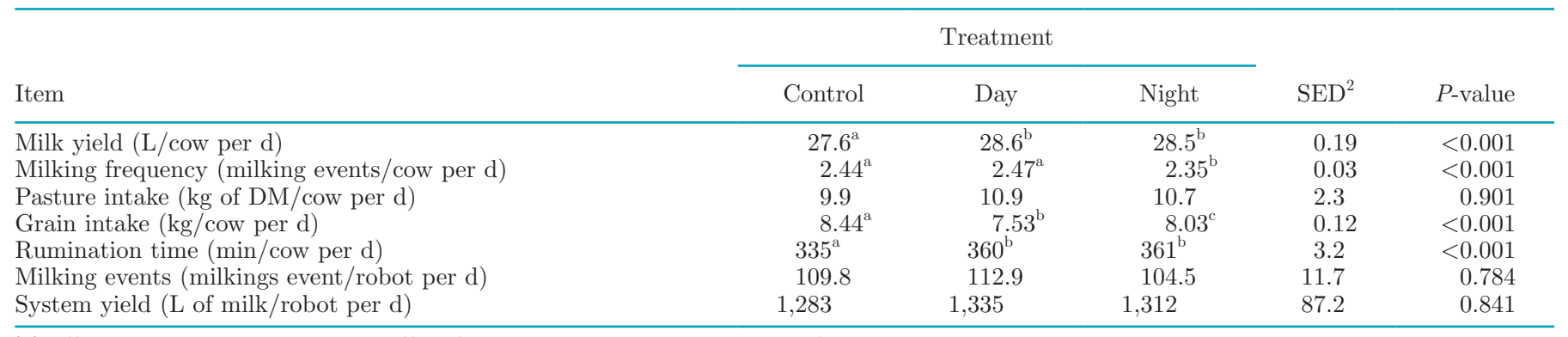

${ }^{\mathrm{a}-\mathrm{c}}$ Different superscripts within an effect for a particular outcome are significant at $P<0.05$.

${ }^{1}$ Includes grazed pasture and silage offered in the paddock.

${ }^{2} \mathrm{SED}=$ standard error of the difference.

intervals were analyzed using GLMM, using the same model as above. The effect of treatment $(T ; i=$ control, day, night) and pasture allocation $(P ; \mathrm{A}, \mathrm{B}, \mathrm{C})$ on cows fetched was determined using REML, with cow $(C ; k=$ $1,2, \ldots, 133)$ and week $(W ; l=1,2, \ldots, 6)$ included as random effects, using the following model:

$$
Y_{i j k l}=T_{i}+P_{j}+T P_{i j}+C_{k}+W_{l}+\varepsilon_{i j k l}
$$

where $Y$ is the dependent variable (cows fetched) and $\varepsilon_{i j k l}$ is the random error.

\section{RESULTS}

Daily pasture intake did not differ $(P=0.901)$ between treatments (Table 4 ). Milk yield was $3.4 \%$ greater $(P<0.001)$ for the day and night treatments compared with the control treatment. Milking frequency was $5 \%$ less $(P<0.001)$ for the night treatment compared with the control and day treatments. Milking events and SY were comparable treatments $(P<0.784$ and $P<0.841$, respectively). Control grain intake was $4.9 \%$ greater than the night treatments, which was in turn $6.2 \%$ greater than the day treatment. Cows spent $25 \mathrm{~min}$ longer ruminating per day during the day and night treatments, compared with the control treatment. The proportion of the herd being milked between 0000 and $0600 \mathrm{~h}$ was $26 \%$ lower for the night treatment compared with control and day treatments. An interaction $(P=$ $0.038, \mathrm{LSD}=17.0)$ was present between treatment and pasture allocation on the number of cows fetched. No difference was observed between treatments for cows fetched from allocation A (control 25.1, day 23.0, and night 20.8 cows/d). The number of cows fetched from the allocation $\mathrm{B}$ did not differ between treatments (control 26.4, day 16.6, and night 14.6 cows/d). Significantly fewer cows required fetching from allocation $\mathrm{C}$ during the control (1.3 cows/d) and night (0 cows/d) treatments, compared with the number of cows fetched from allocation $\mathrm{A}$ under all treatments, and also the allocation B for control. The number of cows fetched from allocation $\mathrm{C}$ during the day $(12.6$ cows/d) treatment did not differ from any other allocation.

A significant interaction $(P<0.001)$ was observed between treatment and hour for RU throughout $24 \mathrm{~h}$ (Figure 1). Throughout pasture allocation B, the night treatment had $24 \%$ more milking events at $0800 \mathrm{~h}$ and $50 \%$ fewer milking events at $1100 \mathrm{~h}$, although milking events were similar across all treatments for the remainder of the allocations. Robot utilization varied throughout pasture allocation $\mathrm{C}$, the largest difference at 1800 and $1900 \mathrm{~h}$, when the night treatment had 83 and $85 \%$ more milking events, respectively, compared with the day treatment. The day treatment had 29 to $44 \%$ more milking events during the first $2 \mathrm{~h}$ (2100 and $2200 \mathrm{~h}$ ) of pasture allocation A compared with the other 2 treatments. The number of milking events increased at $2300 \mathrm{~h}$ for the control treatment, the night treatment recording $31 \%$ fewer milking events at 2300 and $0000 \mathrm{~h}$ than the other 2 treatments.

The proportion of cows presenting for milking between 0000 and $0600 \mathrm{~h}$ was greater $(P<0.001)$ for the control $(43.3 \%)$ and day $(45.3 \%)$ treatments, compared with the night $(25.8 \%)$ treatment. The proportion of milking events with milking intervals exceeding $16 \mathrm{~h}$ was greater $(P<0.05)$ for the control $(2.4 \%)$ treatment compared with the night (1.4\%) treatment, whereas the day $(1.9 \%)$ treatment did not differ from either of the other 2 treatments.

\section{DISCUSSION}

Achieving a high and consistent level of RU throughout $24 \mathrm{~h}$ is key to maximizing efficiency of pasture- 


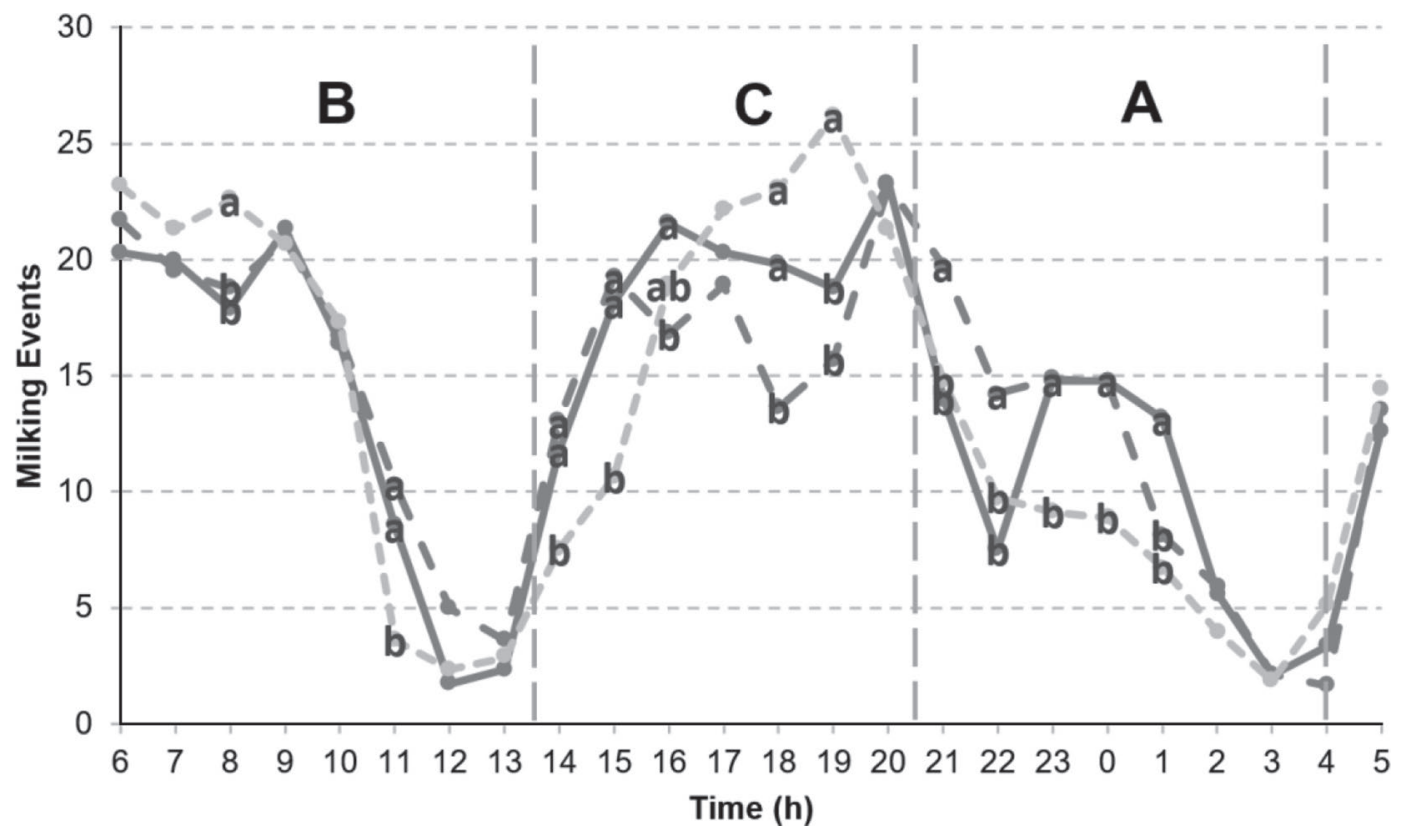

Figure 1. Robot utilization shown as the number of milking events performed per hour for the control (solid line), day (dark gray dashed line), and night (light gray dashed line) treatments. Allocations are denoted by letters (A, B, and C) and vertical dashed lines. Different lowercase letters $(\mathrm{a}-\mathrm{c})$ within the same hour indicate significant differences at $P<0.05$.

based AMS. However, the natural diurnal grazing pattern of cows, which has a major influence on RU, presents a unique challenge for AMS. The objective of this study was to determine the effect of 3 methods of pasture allocation on RU, cow performance, and system performance in a pasture-based AMS. The experiment was conducted with individual treatments applied to the whole herd, as per Lyons et al. (2013), with treatments replicated to account for variation due to time. We showed that RU can be manipulated with the use of variable allocation of pasture (day and night treatments), though variability in RU throughout $24 \mathrm{~h}$ remained.

The variable allocation treatments (day and night) in our study did not eliminate variability in RU, with decreased milking events occurring during the middle of the day and the early morning hours, reflecting the RU patterns currently achieved by commercial pasture-based AMS in Australia (Lyons and Kerrisk 2017). We expected the night treatment, with similar pasture management to John et al. (2013) studies, farm A, would improve the RU during the early morning hours. However, the contrasting results between the 2 studies, coupled with the later changeover from small to large pasture allocation in the study by John et al. (2013; 0200 h, compared with 2100 h in our study), suggests that the timing of pasture allocation, along with variable allocation, are both equally important in achieving a consistent RU throughout 24 h. Further, with 105 milking events occurring between 1600 and $2100 \mathrm{~h}$, and pasture allocation A beginning at 2030 $\mathrm{h}$, the majority of the herd would gain access to the allocation $\mathrm{A}$ as soon as it became available, without requiring to be milked, as milking permission had not yet been granted. As no cows were fetched from pasture allocation $\mathrm{C}$ in the night treatment, we suggest that most cows moved through to pasture allocation $\mathrm{A}$ as soon as it became available and the remainder of the herd volunteered for milking at the beginning of allocation A, when the number of milking events stabilized between 2200 and $0000 \mathrm{~h}$, followed by a further decrease in the number of milking events from midnight onward. This result could be expected, as cow feeding activity decreases from midnight, in most instances (Gibb, 2006; John et al., 2016a). In light of these results, we suggest, coupled with the greater voluntary trafficking associated with the end of the pasture allocation $\mathrm{C}$, shifting the time of access to pasture allocation A back $4 \mathrm{~h}$ may have achieved the objectives of the study. By moving the active access time back $4 \mathrm{~h}$, the smallest pasture allocation would still coincide with the dusk period, when cow grazing activity is greatest, allowing the larger allocation of pasture to encourage voluntary cow traffic between 0000 and $0600 \mathrm{~h}$. Therefore, the influence on cow traffic should be a primary consideration when choosing active access times, along with balancing active access times to fit in with individual farmers daily routine. 
Robot utilization was successfully manipulated within pasture allocation $\mathrm{C}$ by offering different quantities of pasture between each treatment. The night treatment, with less pasture offered during pasture allocation $\mathrm{C}$, featured greater RU toward the end (1800-2000 h) of pasture allocation $\mathrm{C}$, whereas the day treatment recorded $45 \%$ fewer milking events during the same period. We attribute this observation to pasture being depleted more rapidly during smaller pasture allocations, similar to the observations of Ketelaar-de Lauwere et al. (2000), who found cows returned from the paddock to the milking robots more frequently as available pasture biomass decreased. Lyons et al. (2013) also observed $40 \%$ greater MF when smaller quantities of pasture were offered throughout $24 \mathrm{~h}$. Conversely, the larger pasture allocation A offered in the night treatment was detrimental to $\mathrm{RU}$, recording the lowest proportion of milking events between 0000 and $0600 \mathrm{~h}$, though this was likely due to the majority of cows trafficking to allocation A before midnight, as previously highlighted. An increase in milking events occurred at $2000 \mathrm{~h}$ during the day treatment, which could be a result of both dominant and highly motivated cows seeking the first access to pasture by anticipating the gate change (Jago et al., 2003). The higher number of milking events recorded between 2100 and $0100 \mathrm{~h}$ for the control and day treatments are likely due to cows depleting the larger pasture allocation $\mathrm{C}$ at this time (Lyons et al., 2013). Allocation B, with the same quantity of feed offered in all treatments, featured the fewest hours with differences in milking events between treatments. The night treatment recording more milking events at 0800 h, compared with the other treatments, though, did not correspond with an increase in cows fetched at $0730 \mathrm{~h}$. The night treatment also featured fewer milking events at $1100 \mathrm{~h}$, compared with the other treatments, and was likely a result of warmer weather conditions. Based on the evidence presented in the present study, farm managers can be confident in the ability to manipulate short-term RU by changing the quantity of feed offered in individual pasture allocations.

We observed an $80 \%$ reduction in RU between 1100 and $1400 \mathrm{~h}$, coinciding with the hottest part of the day. Heat stress has been proven to have a large effect on DMI, milk production, and activity of cows (West, 2003), and subsequently affect voluntary traffic in AMS. This heat-related behavior has been previously reported by Ketelaar-de Lauwere et al. (1999), who observed cows seeking out shade and water as black globe humidity index increased. A $20 \%$ reduction in RU during the peak heat of the day has also been observed in indoor AMS and was overcome by installing cow cooling at the milking units and modifying the con- centrate feeding regimen (Halachmi, 2004). A paddock shaded by trees was used to provide relief for cows in our study, and as a result, the reduction in RU was much greater compared with the previously mentioned indoor system. The addition of shaded housing near the dairy (Wildridge et al., 2017), in association with a feed-pad, would have helped mitigate the heat stress on the farm in our study while still allowing for a feed allocation to be provided, and could be further aided by cooling at the robot, similar to the study reported by Halachmi (2004). Such methods of heat mitigation represent a significant investment and are not yet commonplace in Australia; however, they do represent a significant opportunity to eliminate reductions in RU during the hottest periods of the day.

The performance of cows in the present study was comparable to commercial farms, with Lyons and Kerrisk (2017) reporting mean MY (24.8 kg of milk/cow per d), MF (2.38 milkings/cow per d), concentrate intake $(6.37 \mathrm{~kg} /$ cow per $\mathrm{d})$, and cows (51 cows/robot) for 8 farms across Australia. System performance also remained relatively consistent throughout the study, despite the contrast in temporal feed allocation between the 3 treatments. An increase in MY occurred during the variable allocation treatments, despite the increased grain intake for the control treatment, which was possibly a compensatory response to changes in pasture intake, as previously seen in the study by Lyons et al. (2013). However, the short treatment length and nature of treatments running successively, rather than concurrently, prevent us from attributing differences in MY entirely to the treatments. The MF for the night treatment was reduced compared with the other treatments, which we associate with reduced number of milking events between 0000 and $0600 \mathrm{~h}$. Although there appeared to be a small effect on individual cows for MY and MF, overall MR and SY per robot remained similar between all treatments. Likewise, DMI was comparable between treatments, highlighting the adaptability of dairy cows to changes in pasture management. However, it should be noted that our calculation of DMI assumed each cow received equal opportunity to graze each pasture allocation, which is not always true for a voluntary traffic system, and the same equation was used to estimate both rye-grass and clover-based swards, though this error would be the same for all treatments. The clover-based sward was only grazed twice during the experiment (December 3 and 7 in allocation $\mathrm{C}$ ) and we expect this would have had minimal effect on cow traffic. When grazed soybean (Glycine max) was incorporated into kikuyu grass (Pennisetum clandestinum Hoach ex Chiov.) pasturebased AMS, cows exited the pasture allocation more 
slowly (Clark et al., 2014); however, we did not observe this in our study. Other studies investigating feeding frequency in a controlled environment (Dalley et al., 2001) and pasture-based AMS (Lyons et al., 2013) likewise found no difference in daily DMI. Similarly, a study of "inaccurate" pasture allocation in an AMS, where the quantity of pasture offered between allocations varied, compared with pasture being allocated consistently, found similar DMI for both treatments (Dickeson, 2010). Clark et al. (2016) has shown that pasture utilization is comparable between conventional milking systems and AMS (13.5 t of DM/ha per yr), with pregrazing and postgrazing biomass ranging from 2,200 to $2,500 \mathrm{~kg}$ of $\mathrm{DM} / \mathrm{ha}$ and 1,400 to $1,500 \mathrm{~kg}$ of $\mathrm{DM} /$ ha, respectively. Mean pregrazing biomass (2097 $\mathrm{kg}$ of $\mathrm{DM} / \mathrm{ha}$ ) was slightly lower during the present study; however, mean postgrazing biomass $(1,534 \mathrm{~kg}$ of $\mathrm{DM} / \mathrm{ha}$ ) was maintained at a similar level to that of Clark et al. (2016). The consistency of these factors between each treatment should provide farm managers with confidence to change their pasture management when required, without the risk of having a major negative effect on overall system performance.

\section{CONCLUSIONS}

Our study demonstrated the ability to manipulate RU within individual pasture allocations, by varying the quantity of feed offered within the allocation. Based on the evidence presented in our study, farm managers can be confident in the ability to manipulate shortterm RU by changing the quantity of feed offered in individual allocations. However, variable allocation did not eliminate the reduction in RU between 0000 and 0600 h. From our results, combined with those of other studies in the literature, we postulate that the timing of pasture allocation, along with variable allocation as used in this study, are both equally important in achieving a consistent RU throughout $24 \mathrm{~h}$. Further research is required to determine how variable allocation, and timing of feed allocation, can be used together to improve RU in pasture-based AMS.

\section{ACKNOWLEDGMENTS}

We acknowledge the support of The University of Melbourne farm manager, Ashley Gabler, and farm staff at the Dookie dairy in conducting the experiment, the Dairy Research Foundation for its support of the Dairy Science Group, and the investors of the FutureDairy project (Dairy Australia, NSW Department of Primary Industries, The University of Sydney, and DeLaval). The authors acknowledge Evelyn Hall (The University of Sydney, Camden, Australia) for her statistical input.

\section{REFERENCES}

AFIA. 2014. AFIA-Laboratory Method Manual (03/001), Australian Fodder Industry Association Inc. Melbourne, Australia.

Ankom Technologies. 2014a. Acid Detergent Fiber in Feeds: Filter Bag Technique (for A200 and A200I). ANKOM Technologies, Macedon, NY.

Ankom Technologies. 2014b. Neutral Detergent Fiber in Feeds: Filter Bag Technique (for A200 and A200I). ANKOM Technologies, Macedon, NY.

AOAC International. 1995. Official Methods of Analysis. 16th ed. AOAC International, Arlington, VA.

Bach, A., C. Iglesias, S. Calsamiglia, and M. Devant. 2007. Effect of amount of concentrate offered in automatic milking systems on milking frequency, feeding behavior, and milk production of dairy cattle consuming high amounts of corn silage. J. Dairy Sci. 90:5049-5055.

Clark, C. E. F., S. R. Farina, S. C. Garcia, M. R. Islam, K. L. Kerrisk, and W. J. Fulkerson. 2016. A comparison of conventional and automatic milking system pasture utilization and pre- and postgrazing pasture mass. Grass Forage Sci. 71:153-159.

Clark, C. E. F., A. Horadagoda, K. L. Kerrisk, V. Scott, M. R. Islam, R. Kaur, and S. C. Garcia. 2014. Grazing soybean to increase voluntary cow traffic in a pasture-based automatic milking system. Asian-Australas. J. Anim. Sci. 27:422-430.

Dalley, D. E., J. R. Roche, P. J. Moate, and C. Grainger. 2001. More frequent allocation of herbage does not improve the milk production of dairy cows in early lactation. Aust. J. Exp. Agric. 41:593599.

DeVries, T. J., M. A. G. von Keyserlingk, and K. A. Beauchemin. 2005. Frequency of feed delivery affects the behavior of lactating dairy cows. J. Dairy Sci. 88:3553-3562.

Dickeson, D. 2010. Quantification of the effects of inaccurate pasture allocation in a pasture based automatic milking system. Pages 136-138 in Dairy Research Foundation's 2010 Symposium. Vol. 15, Camden, NSW, Australia.

Earle, D., and A. McGowan. 1979. Evaluation and calibration of an automated rising plate meter for estimating dry matter yield of pasture. Anim. Prod. Sci. 19:337-343.

Gibb, M. 2006. Grassland management with emphasis on grazing behaviour. Frontis 18:141-157.

Halachmi, I. 2004. Designing the automatic milking farm in a hot climate. J. Dairy Sci. 87:764-775.

Halachmi, I. 2009. Simulating the hierarchical order and cow queue length in an automatic milking system. Biosyst. Eng. 102:453-460.

Halachmi, I., S. Ofir, and J. Miron. 2005. Comparing two concentrate allowances in an automatic milking system. Anim. Sci. J. 80:339-343.

Jago, J., A. Jackson, and M. Woolford. 2003. Dominance effects on the time budget and milking behaviour of cows managed on pasture and milked in an automated milking system. Pages 120-123 in Proceedings of the New Zealand Society of Animal Production, Queenstown, New Zealand.

John, A., C. Clark, M. Freeman, K. Kerrisk, and R. Rawnsley. 2013. Pasture Management in Two High Performing Automatic Milking Systems. Pages 99-103 in Dairy Research Foundation's 2013 Symposium. Vol. 18, Kiama, Australia.

John, A., S. Garcia, M. Freeman, K. Kerrisk, and C. Clark. 2016a. Diurnal feeding patterns of dairy cattle and implications for automatic milking systems. Pages 80-85 in Dairy Research Foundation's 2016 Symposium. Wagga Wagga, Australia.

John, A. J., C. E. F. Clark, M. J. Freeman, K. L. Kerrisk, S. C. Garcia, and I. Halachmi. 2016b. Review: Milking robot utilization, a successful precision livestock farming evolution. Animal 10:1484-1492.

Kerrisk, K. 2010. Management Guidelines for Pasture-Based AMS Farms. Dairy Australia, Melbourne, Victoria.

Ketelaar-de Lauwere, C. C., A. H. Ipema, C. Lokhorst, J. H. M. Metz, J. P. T. M. Noordhuizen, W. G. P. Schouten, and A. C. Smits. 2000. Effect of sward height and distance between pasture and barn on cows' visits to an automatic milking system and other behaviour. Livest. Prod. Sci. 65:131-142. 
Ketelaar-de Lauwere, C. C., A. H. Ipema, E. N. J. van Ouwerkerk, M. M. W. B. Hendriks, J. H. M. Metz, J. P. T. M. Noordhuizen, and W. G. P. Schouten. 1999. Voluntary automatic milking in combination with grazing of dairy cows-Milking frequency and effects on behaviour. Appl. Anim. Behav. Sci. 64:91-109.

Lyons, N. A., and K. L. Kerrisk. 2017. Current and potential system performance on commercial automatic milking farms. Anim. Prod. Sci. 57:1550-1556.

Lyons, N. A., K. L. Kerrisk, and S. C. Garcia. 2013. Comparison of 2 systems of pasture allocation on milking intervals and total daily milk yield of dairy cows in a pasture-based automatic milking system. J. Dairy Sci. 96:4494-4504.

Oddy, V., G. Robards, and S. Low. 1983. Prediction of in vivo dry matter digestibility from the fibre and nitrogen content of a feed. Pages 395-398 in Feed information and animal production: Proceedings of the Second Symposium of the International Network of Feed Information Centres, Slough, UK.

Prescott, N., T. Mottram, and A. Webster. 1998. Relative motivations of dairy cows to be milked or fed in a Y-maze and an automatic milking system. Appl. Anim. Behav. Sci. 57:23-33.
Primary Industries Standing Committee. 2007. Nutrient Requirements of Domesticated Ruminants, CSIRO Publishing, Collingwood, Australia.

Stobbs, T. 1970. Automatic measurement of grazing time by dairy cows on tropical grass and legume pastures. Trop. Grassl. 4:237244.

West, J. W. 2003. Effects of heat-stress on production in dairy cattle. J. Dairy Sci. 86:2131-2144.

Wildridge, A. M., S. C. Garcia, P. C. Thomson, E. C. Jongman, C. E. F. Clark, and K. L. Kerrisk. 2017. The impact of a shaded premilking yard on a pasture-based automatic milking system. Anim. Prod. Sci. 57:1219-1225.

Woolford, M. W., R. W. Claycomb, J. Jago, K. Davis, I. Ohnstad, R. Wieliczko, P. J. A. Copeman, and K. Bright. 2004. Automatic dairy farming in New Zealand using extensive grazing systems. Pages 280-285 in Conf. Proc. Automatic Milking: A Better Understanding, Lelystad, the Netherlands. Wageningen Academic Publishers, Wageningen, the Netherlands. 